\title{
Platelet-rich plasma plays an antibacterial, anti-inflammatory and cell proliferation-promoting role in an in vitro model for diabetic infected
} wounds

This article was published in the following Dove Medical Press journal:

Infection and Drug Resistance

Tao Li, ' Yu Ma, ${ }^{2}$ Min Wang, ' Tao

Wang, ${ }^{3}$ Jing Wei, ${ }^{4}$ Rui Ren, ${ }^{\prime}$ Min

He,' Guixue Wang, ${ }^{2}$ Johnson

Boey, ${ }^{5}$ David G Armstrong, ${ }^{6}$

Wuquan Deng, ${ }^{2}$ Bing Chen'

'Department of Endocrinology, Southwest Hospital, Army Medical University,

Chongqing, People's Republic of

China; ${ }^{2}$ Department of Endocrinology and Nephrology, Key Laboratory for

Biorheological Science and Technology of Ministry of Education, Chongqing University, Affiliated Central Hospital of

Chongqing University, Chongqing, People's Republic of China; ${ }^{3}$ Institute of Combined Injury, State Key Laboratory of Trauma, Burn and Combined Injury, Army Medical University, Chongqing, People's Republic of China; ${ }^{4}$ Department of Endocrinology, General Hospital of Xinjiang Military Region, The Chinese People's Liberation Army, Urumqi, People's Republic of China; ${ }^{5}$ Department of Podiatry, Singapore General Hospital, Singapore; 'Southwestern Academic Limb Salvage Alliance (SALSA), Department of Surgery, Keck School of Medicine of the University of Southern California, Los Angeles, CA, USA

Correspondence: Wuquan Deng Department of Endocrinology and Nephrology, Key Laboratory for Biorheological Science and Technology of Ministry of Education,

Chongqing University, Affiliated Central Hospital of Chongqing University, I Health Road, Yuzhong District, Chongqing 4000I4,

People's Republic of China

Tel +862363692185

Email wuquandeng@gmail.com

Bing Chen

Department of Endocrinology, Southwest Hospital, Army Medical University, 30 Gaotanyan Street, Shapingba District,

Chongqing 400038, People's Republic of China

Tel +86236875 4l 38

Email chenbing3@medmail.com.cn
Aim: This study was designed to examine the potential mechanism underlying these roles of platelet-rich plasma in treating diabetic foot ulcers (DFUs).

Methods: Staphylococcus aureus and HaCaT were co-cultured under high glucose conditions to serve as an in vitro model for infected cells in DFUs. Platelet-rich gel (PRG) or extract liquid of platelet-rich gel (EPG) were used to interfere with the model to observe the growth of HaCaT cells and $S$. aureus, and the effect of miR-21 changes in HaCaT cells on PDCD4, NF- $\kappa$ B activity and related inflammatory factors.

Results: Incubation of $\mathrm{HaCaT}$ cells with $S$. aureus promoted the decline of cell proliferation. Under this condition, the level of PDCD4 and the activity of NF- $\kappa B$ were increased in HaCaT cells with concomitant increased of IL-6, TNF- $\alpha$ and decreased IL-10, TGF- $\beta 1$ in cultured supernatant. Both of PRG and EPG exhibited specific anti-S. aureus activity where they protect $\mathrm{HaCaT}$ cells from bacterial damage and promote cell proliferation. Meanwhile, EPG was observed to increase intracellular miRNA-21 while reduce PDCD4 expression and inhibit NF- $\mathrm{\kappa B}$ activity to suppress the inflammation in HaCaT cells.

Conclusion: This in vitro model provides a valuable tool for study of wound healing in the treatment of DFUs. Our results suggest that miRNA-21 may regulate the expression of NF- $\kappa B$ through PDCD4 where it plays an anti-inflammatory role and promote proliferation in infected DFUs treated by PRP. These findings could provide novel therapeutic targets for refractory wounds. Keywords: platelet-rich plasma, antibacterial, anti-inflammatory, cell proliferation-promoting, diabetic infected wound

\section{Introduction}

The global incidence of diabetes mellitus is increasing rapidly. The International Diabetes Federation estimated that there will be $\sim 630$ million of people diagnosed with diabetes by $2045 .{ }^{1}$ Among the complications associated with diabetes, diabetic foot ulcers (DFUs) severely debilitate the quality of life, and it was found that one in four individuals diagnosed with diabetes will develop DFU in their lifetime. ${ }^{2}$ Many pathophysiological mechanisms have been proposed to explain delayed wound healing in DFUs, one of which, wound infection plays an important role. ${ }^{3}$ Gram-positive bacterial infections are relatively common in DFUs, predominately caused by Staphylococcus aureus. ${ }^{4}$ Bacterial colonization in wounds causes direct cellular damage to the host cell, and an imbalance in the microenvironment. Once the bacterial bioburden reaches a critical level, the host body mounts an immune response, which is often deranged and 
yet insufficient to eradicate the offending bacteria. Persistent inflammation ensues, which further impedes diabetic wound healing. ${ }^{5,6}$ Antibiotics are often used to treat wound infections in DFUs. However, the frequent recurrence of DFUs for patients in DFU remission and emergence of multiple-drug resistance bacteria rendered antibiotics ineffective or poor efficacy, when used alone..$^{2,7}$

In recent years, studies has revealed the wound healing potential of platelet-rich plasma (PRP) in the treatment of DFUs from their antimicrobial and regenerative properties. ${ }^{8-10}$ Platelet-rich gel (PRG) is produced from PRP which is activated by thrombin and/or calcium. These platelet derivatives have been shown to possess several important functions such as antibacterial and promotion of wound healing. For example, PRG has been proven to inhibit S. aureus, Staphylococcus epidermidis, Escherichia coli and Klebsiella pneumoniae, as well as methicillin-resistant staphylococcus aureus in a previous study. ${ }^{11}$ Moreover, PRG does not cause drug resistance and has a synergistic effect with antibiotics. The combination of these characteristics makes it more promising over traditional antibiotic prescriptions. ${ }^{12}$

Within activated platelets, platelet-derived antimicrobial peptides, chemokines, growth factors, and miRNAs have been observed to exert antibacterial effects and promote wound healing. ${ }^{13}$ There are more than 200 miRNAs found in platelets, in particularly, miRNA-21 and miRNA-223 are highly abundant. ${ }^{14}$ The level of miRNAs in DFU is directly correlated to wound healing. ${ }^{15}$ The expression of miR-21 is up-regulated during wound healing while the suppression of its expression is found in wounds of diabetic mice. ${ }^{16}$ Taken the above literature together, it has been speculated that miRNA21 may play an important role in PRG treatment of DFUs. Furthermore, it has been reported that miRNA-21 can also play a role in inflammation by regulating nuclear factor-kappa $(\mathrm{NF}-\kappa \mathrm{B}),{ }^{17}$ but the exact mechanism is not yet clear.

Programmed cell death factor 4 (PDCD4) is one of the currently validated miRNA-21 regulatory targets in which miRNA-21 inhibit PDCD4 expression at the posttranscriptional level. ${ }^{18,19}$ It has been reported that inhibition of miRNA-21 expression in mice may up-regulate PDCD4, induce the activation of NF- $\mathrm{KB}$ which eventually leads to increased synthesis of pro-inflammatory cytokines, and decreased synthesis of anti-inflammatory cytokines. ${ }^{20}$ Based on the above findings, we hypothesize that PRG may affect the activity of $\mathrm{NF}-\kappa \mathrm{B}$, regulate wound inflammation, and promote wound healing through regulating PDCD4 mediated by miRNA- 21 .

To confirm this assumption, we firstly devised a diabetic wound infected in-vitro study model. The PRG was subsequently added into this model to observe the growth of $\mathrm{HaCaT}$ cells and $S$. aureus. In addition, to evaluate the potential ability of PRP in antibacterial and wound healing, the changes in miRNA-21, PDCD4 and NF- $\kappa$ B in HaCaT cells and related inflammatory factors were assessed.

\section{Materials and methods \\ Preparation of platelet-poor plasma (PPP) and PRP}

Whole blood samples were drawn from 21 patients (age $69 \pm 12$ ) with DFUs but free of active infection and existing systemic coagulation disorders. PPP was isolated from the blood specimens with the first centrifugation in the department of blood transfusion. Platelets were sequestered by full automatic blood separator (CS-3000 plus; Baxter International, Inc., Deerfield, IL, USA), and condensed by the second centrifugation to produce PRP. The concentrations of platelets in PRP and PPP were determined by the automatic hematology analyzer (KX-21N; Sysmex Corporation, Kobe, Japan). The average platelet count was $(1024 \pm 111) \times 10^{9} / \mathrm{L}$ in PRP, while it was $<10 \times 10^{9} / \mathrm{L}$ in PPP. The majority of the extracted PRP was used to treat the blood donor's DFUs while the remaining PRP will be used in our study. The above processes were approved by the institutional review board of the first hospital affiliated to the Army Medical University. Written informed consent was obtained from all patients. The study was approved by the medical ethics committee of the first hospital affiliated to the Army Medical University (Chongqing, People's Republic of China) and conducted in compliance with the Declaration of Helsinki.

\section{Preparation of PRG}

The PRG was harvested by platelet activation. The $10 \mathrm{~mL}$ PRP was activated by $1 \mathrm{~mL}$ calcium gluconate solution $(100 \mathrm{~g} / \mathrm{L})$ and $1,000 \mathrm{IU}$ thrombin.

\section{Preparation of the extract liquid from PRG}

The PRG was incubated at $37^{\circ} \mathrm{C}$ for 1 hour with constant thorough stirring with a sterile glass rod. Then, the mixture was centrifuged for 15 minutes with a centrifugation force of $3,000 \times g$ at room temperature. The supernatant was collected as extract liquid of platelet-rich gel (EPG).

\section{Establishment of an in vitro diabetic infected wound model}

HaCaT cells and S. aureus (ATCC 25923) were bestowed gifts from the Institute of Combined Injury of the Army 
Medical University (Chongqing, People's Republic of China) for research purposes. $S$. aureus was cultured in Tryptic Soy Broth (TSB) medium in a shaking $37^{\circ} \mathrm{C}$ incubator overnight. Then, the cultured bacteria were collected by centrifugation and re-suspended in high glucose DMEM culture medium (Hyclone). Bacterial density was adjusted to $10^{8} \mathrm{CFU} / \mathrm{mL}$ and serial dilutions were prepared. Simultaneously, HaCaT cells were cultured in high glucose DMEM supplemented with $10 \% \mathrm{FBS}$ at $37^{\circ} \mathrm{C}$ with $5 \% \mathrm{CO}_{2}$ for 4 days. Then cells were harvested and seeded into 96-well plates at a density of 30,000 cells $/ \mathrm{cm}^{2}$. After 48 hours, the culture medium was replaced by either fresh high glucose DMEM (HaCaT control) or S. aureus dilutions. To examine potential damage ability to $\mathrm{HaCaT}$ cells, four serial bacterial concentrations, from 10 to $10^{4} \mathrm{CFU} / \mathrm{mL}$, were chosen to set up the co-culture system. After pre-incubation of $\mathrm{HaCaT}$ cells with $S$. aureus for 1 hour, PRG or EPG accounted for different volume ratio was added to the co-culture system. In addition, in order to observe the direct effect on $\mathrm{HaCaT}$ cells, EPG was also added to the cell culture medium without bacteria. After 12, 24, 36 and 48 hours of intervention, cell proliferation was determined by Cell Counting Kit- 8 (CCK-8) assay. Western blotting, quantitative reverse transcription (qRT-PCR), immunofluorescence and ELISA were used to determine the expression of miRNA, protein and cytokines, and the co-culture system was established in 6-well plates and divided into four groups: the H group, culture of $\mathrm{HaCaT}$ cells alone; the HP group, uninfected $\mathrm{HaCaT}$ cells interfered with EPG; the HS group, co-culture of HaCaT cells with $S$. aureus; and the HSP group, $S$. aureus-infected $\mathrm{HaCaT}$ cells interfered with EPG. The components of the co-culture system are shown in Table 1.

\section{Evaluation of antibacterial activity}

To compare the differential antibacterial ability of PRG and EPG, the bacterial concentration of $10^{4} \mathrm{CFU} / \mathrm{mL}$ was chosen. Either PRG or EPG was prepared from equivalent PRP. After 12, 24, 48 and 72 hours of intervention, the bacteria were quantified by plate colony counting method. Furthermore, the antibacterial performance of EPG accounting for 10\%, 20\% and $30 \%$ volume were tested after 24 hours of intervention in the co-culture system with the initial bacterial concentration as $10^{6} \mathrm{CFU} / \mathrm{mL}$.

\section{CCK-8 assay}

Cell proliferation was measured according to the instructions of CCK-8. Briefly, $100 \mu \mathrm{L}$ of DMED containing 10
Table I Components of the four co-culture groups

\begin{tabular}{|c|c|c|c|c|}
\hline Component $\quad$ Group & H & HP & HS & HSP \\
\hline DMEM & $1.6 \mathrm{~mL}$ & $1.6 \mathrm{~mL}$ & $1.4 \mathrm{~mL}$ & $1.4 \mathrm{~mL}$ \\
\hline S. aureus ${ }^{\mathrm{a}}$ & - & - & $0.2 \mathrm{~mL}$ & $0.2 \mathrm{~mL}$ \\
\hline EPG & - & $0.4 \mathrm{~mL}$ & - & $0.4 \mathrm{~mL}$ \\
\hline PPP & $0.4 \mathrm{~mL}$ & & $0.4 \mathrm{~mL}$ & - \\
\hline
\end{tabular}

Notes: aStaphylococcus aureus suspension was diluted with high glucose DMEM to $10,000 / \mathrm{mL}$. The $\mathrm{H}$ group, culture of $\mathrm{HaCaT}$ cells alone; the HP group, uninfected $\mathrm{HaCaT}$ cells interfered with EPG; the HS group, co-culture of $\mathrm{HaCaT}$ cells with $S$. aureus; and the HSP group, S. aureus-infected $\mathrm{HaCaT}$ cells interfered with EPG. Abbreviations: EPG, extract liquid of platelet-rich gel; PPP, platelet-poor plasma; S. aureus, Staphylococcus aureus.

$\mu \mathrm{L}$ of CCK-8 solution was added to each well and the plate was incubated for 2 hours at $37^{\circ} \mathrm{C}$. Then the OD of wells was measured at $450 \mathrm{~nm}$ using a microtiter plate reader. Cell proliferation of experimental groups was expressed as a percentage of the $\mathrm{HaCaT}$ control group. There is a linear relationship between cell number and OD.

\section{Plate colony counting}

The bacterial suspension or cell lysate were collected and underwent serial dilution of up to seven times. Then $100 \mathrm{uL}$ from each dilution was plated onto TSB agar plates. After incubation overnight at $37^{\circ} \mathrm{C}$, the number of bacterial colonies was counted manually. The dilution times were adjusted to ensure the number of colonies in each plate was between 30 and 300 .

\section{Quantitative reverse transcription}

Total RNA from HaCaT cells was extracted by Trizol (Thermo Fisher Scientific, Waltham, MA, USA). The purity of isolated RNA was determined by Nanodrop ND-1000 (Thermo Fisher Scientific). Reverse transcription was performed with PrimeScript RT reagent Kit (Takara Bio Inc., Kusatsu, Shiga, Japan). Quantitative PCR of miRNA21, IL-6, IL-10, tumor-necrosis factor alpha (TNF- $\alpha$ ) and TGF- $\beta 1$ were performed using Mir-X ${ }^{\mathrm{TM}}$ miRNA SYBR ${ }^{\circledR}$ Kit, TB Green ${ }^{\mathrm{TM}}$ Premix Ex Taq ${ }^{\mathrm{TM}}$ II (Takara Bio Inc.) and iQ5 (Bio-Rad Laboratories Inc., Hercules, CA, USA) detection system supplied with analytical software. Primers were synthesized by RiboBio Co. Ltd (Guangzhou, People's Republic of China). Forward (F) and reverse (R) primers are described in Table 2. The PCR results were normalized with U6 snRNAs for miR-21, and $\beta$-actin mRNAs for IL-6, IL-10, TNF- $\alpha$ and TGF- $\beta 1$ as internal controls respectively. Results were expressed as relative expression compared with control samples. 


\section{Western blotting}

Total proteins from $\mathrm{HaCaT}$ cells were extracted by cell lysis buffer, containing supplementary protease and phosphatase inhibitor. Then, the proteins were subjected to SDS-PAGE and transferred to polyvinylidene fluoride membrane. Subsequently, the membrane was blocked with 5\% non-fat dry milk in tris buffered saline with Tween 20 buffer and incubated with primary antibodies at $4^{\circ} \mathrm{C}$ overnight, followed by incubation with secondary antibodies at $37^{\circ} \mathrm{C}$ for 1 hour. Protein blots were visualized with super-efficient chemiluminescence kit and detected by ChemiDoc XRS device (Bio-Rad Laboratories Inc.) supplied with Image Lab software. Antibodies purchased from Cell Signaling Technology (Danvers, MA, USA) were as follows: rabbit anti-PDCD4 antibody, rabbit anti- $\beta$-actin antibody, rabbit anti- phosphoNF- $\kappa$ B p 65 antibodyand horseradish peroxidase-conjugated goat anti-rabbit IgG.

\section{Immunofluorescence analysis}

Sterile coverslips were pre-placed into a 6-well plate, then HaCaT cells were seeded on the coverslips and the co-culture system of each group was performed according to Table 1. After EPG intervention for 12, 24 and 48 hours, the cells were washed three times by PBS and fixed in 4\% paraformaldehyde for 15 minutes. Subsequently the cells were treated with $0.5 \%$ Triton $\mathrm{X}-100$ for 20 minutes, blocked with $10 \%$ goat serum at $37^{\circ} \mathrm{C}$ for 30 minutes and incubated with NF- $\kappa B$ p65 antibodies (1:200; Cell Signaling Technology) at $4^{\circ} \mathrm{C}$ overnight, followed by incubation with $\mathrm{Cy} 3$-conjugated secondary antibodies at $37^{\circ} \mathrm{C}$ for 30 minutes. Then the cell nucleus was stained with a DAPI for 5 minutes at room temperature. After rinsing with $\mathrm{PBS}$, the coverslips were mounted on glass slides and observed under a fluorescence microscope.

\section{ELISA}

Cell culture supernatants in the four groups were collected for cytokine evaluation. The level of IL-6, IL-10, TNF- $\alpha$, TGF$\beta 1$ were measured by enzyme immunoassay kit (Bosterbio, Wuhan, People's Republic of China). The content of cytokines was calculated through a standard curve obtained by measuring the standards.

\section{Statistical analysis}

Data were expressed as mean \pm SD. One-way ANOVA and LSD tests were used to analyze all experimental data. Analysis was carried out by SPSS 20.0 (IBM Corporation, Armonk, NY, USA). We used an alpha of $5 \%(* P<0.05 ; * * P<0.01)$.

\section{Results}

\section{Effect of S. aureus on the proliferation of $\mathrm{HaCaT}$ cells}

Using the proposed co-culture system in-vitro model for infected cells in DFUs, we found that increasing initial concentrations of $S$. aureus results in a dose-dependent decline

Table 2 Primers used in the study

\begin{tabular}{|c|c|c|}
\hline Primers & \multicolumn{2}{|l|}{ Sequences $\left(5^{\prime} \rightarrow 3^{\prime}\right)$} \\
\hline \multicolumn{3}{|c|}{ Reverse transcription PCR } \\
\hline U6 & AAAATATGGAACGCTTCACG & \\
\hline miR-2I & CTCAACTGGTGTCGTGGAGTCGGCAATTCAGTTGAGTCAACATC & \\
\hline \multicolumn{3}{|c|}{ Primers used for RT-qPCR } \\
\hline \multirow[t]{2}{*}{ U6 } & Forward & CGCTTCGGCAGCACATATACTAAAATTGGAAC \\
\hline & Reverse & GCTTCACGAATTTGCGTGTCATCCTTGC \\
\hline \multirow[t]{2}{*}{ miR-2I } & Forward & ACACTCCAGCTGGGTAGCTTATCAGACTGA \\
\hline & Reverse & TGGTGTCGTGGAGTCG \\
\hline \multirow[t]{2}{*}{ IL-6 } & Forward & ACTCACCTCTTCAGAACGAATTG \\
\hline & Reverse & CCATCTTTGGAAGGTTCAGGTTG \\
\hline \multirow[t]{2}{*}{ IL-10 } & Forward & TCAAGGCGCATGTGAACTCC \\
\hline & Reverse & GATGTCAAACTCACTCATGGCT \\
\hline \multirow[t]{2}{*}{ TNF- $\alpha$} & Forward & ССТСТСТСТАATCAGСССТСТG \\
\hline & Reverse & GAGGACCTGGGAGTAGATGAG \\
\hline \multirow[t]{2}{*}{ TGF- $\beta$ I } & Forward & GGCCAGATCCTGTCCAAGC \\
\hline & Reverse & GTGGGTTTCCACCATTAGCAC \\
\hline \multirow[t]{2}{*}{$\beta$-actin } & Forward & CTTAGTTGCGTTACACCCTTTCTT \\
\hline & Reverse & CACCTTCACCGTTCCAGTTTT \\
\hline
\end{tabular}

Abbreviation: TNF- $\alpha$, tumor-necrosis factor alpha. 
of $\mathrm{HaCaT}$ cells proliferation (Figure 1). For instance, there was significant reduction in cell proliferation after co-culture for 12 hours at a baseline bacterial concentration of $10^{3} \mathrm{CFU} /$ $\mathrm{mL}(P<0.05)$. Furthermore, independent to the initial concentration of bacteria, cell proliferation was severely impaired after 36 hours of co-culture $(P<0.01)$ and almost complete destroyed by bacteria after 48 hours $(P<0.01)$.

\section{The antibacterial effect of PRG and EPG}

Initially, the baseline bacterial concentration was set at $10^{4}$ $\mathrm{CFU} / \mathrm{mL}$ to evaluate the antibacterial activity of PRG and EPG (Figure 2A). Compared to the PPP group, both PRG and EPG had a significant reduction in bacterial count within 12 hours $(P<0.01)$. In the next 36 hours, there were gradual increases in the bacterial counts but there were no statistical differences between the two groups $(P<0.05)$. Moreover, in the previous 24 hours, the EPG group exhibited a higher bacterial growth rate than the PRG group $(P<0.05)$. Secondly, the higher initial bacterial concentration $\left(10^{6} \mathrm{CFU} / \mathrm{mL}\right)$ was used to further assess the antibacterial activity of EPG. It was found that the bacterial count decreased considerably after EPG intervention for 24 hours $(P<0.05)$ and this antibacterial effect was concentration dependent. For instance, 30\% EPG suppressed the extracellular (Figure 2B) and intracellular (Figure $2 \mathrm{C})$ bacteria concentration significantly $(P<0.01)$.

\section{EPG protects cells from bacterial damage and promotes cell proliferation}

In Figure 3, EPG demonstrate that it could protect $\mathrm{HaCaT}$ cells from $S$. aureus with an initial bacterial concentration of $10^{3} \mathrm{CFU} / \mathrm{mL}$. Cell proliferation was restored in the first
24 hours with $20 \%$ EPG and promotion of cell proliferation occurred during the next 24 hours, while 10\% EPG was unable to achieve this effect. Compared to the control group, cell proliferation was stimulated after 36 hours in a concentration-dependent manner when EPG was added to $\mathrm{HaCaT}$ cells in the absence of $S$. aureus infection.

\section{EPG regulate miRNA-2I, PDCD4 and NF- $\kappa B$ signaling pathway activity in $\mathrm{HaCaT}$ cells}

Before extraction of RNA from $\mathrm{HaCaT}$ cells, the four groups were photographed with an inverted microscope (Figure 4). In the HS group, there were hardly any viable cells while EPG displayed remarkable antibacterial effect in the HSP group. Increased cell proliferation was observed more in $\mathrm{HaCaT}$ cells in the HP group than in the $\mathrm{H}$ group at 48 hours after treatment with EPG. As Figure 5 illustrates, in the early stage at the 12 th hour, application of $20 \%$ EPG did not cause significant changes to miRNA-21 in the experimental group. But at the 24th hour, increased miRNA-21 level was observed in the HSP group. Meanwhile, miRNA-21 level in the HP group was significantly increased after 24 and 48 hours of EPG intervention. At the 48th hour, due to the extensive damage caused by bacteria in the co-culture system, insufficient RNA was extracted from residual $\mathrm{HaCaT}$ cells in the HS group. Thus, no data were available for comparison of HS and HSP groups. Moreover, miRNA-21 level was found to be elevated in the HP group, and this elevation was more pronounced at the 48th than the 24th hour when compared to the $\mathrm{H}$ group. In the setting of bacterial infection, the expression of PDCD4 and $\mathrm{p}-\mathrm{NF}-\mathrm{\kappa B}$ p 65 protein was greatly

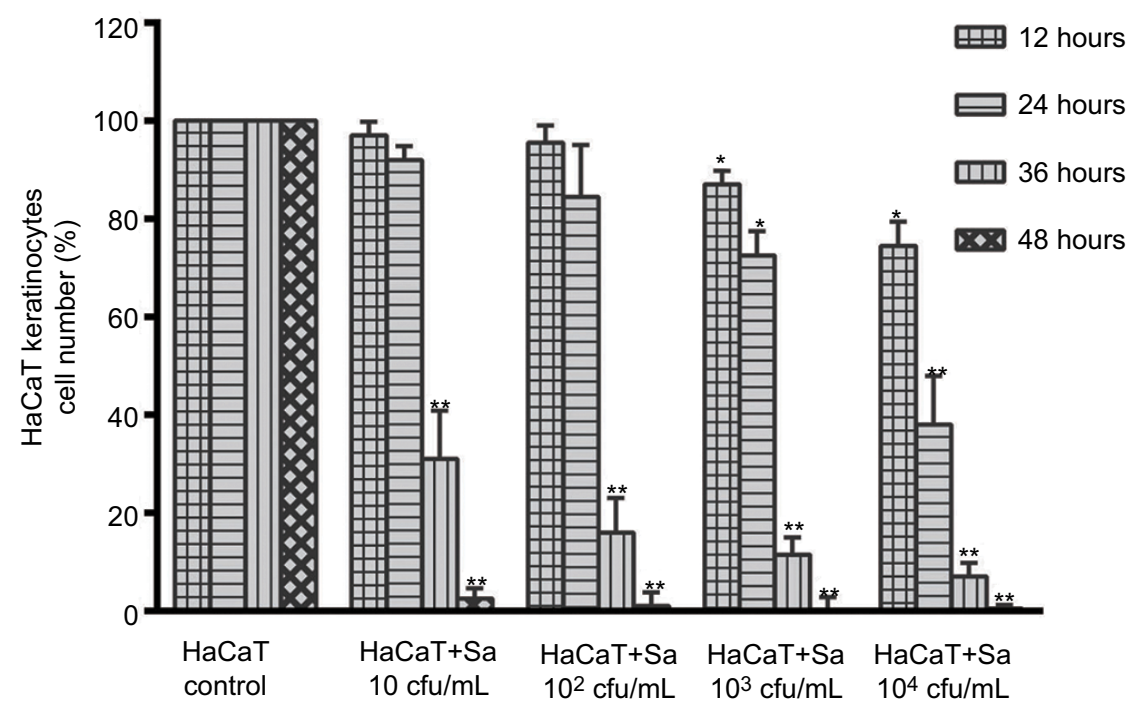

Figure I Incubation of $\mathrm{HaCaT}$ cells with increasing starting concentrations of Staphylococcus aureus led to a dose-dependent decline of the cell proliferation. Notes: Significant deviations from the $\mathrm{HaCaT}$ control at the respective incubation time $(* P<0.05 ; * * P<0.0 \mathrm{I})$. 

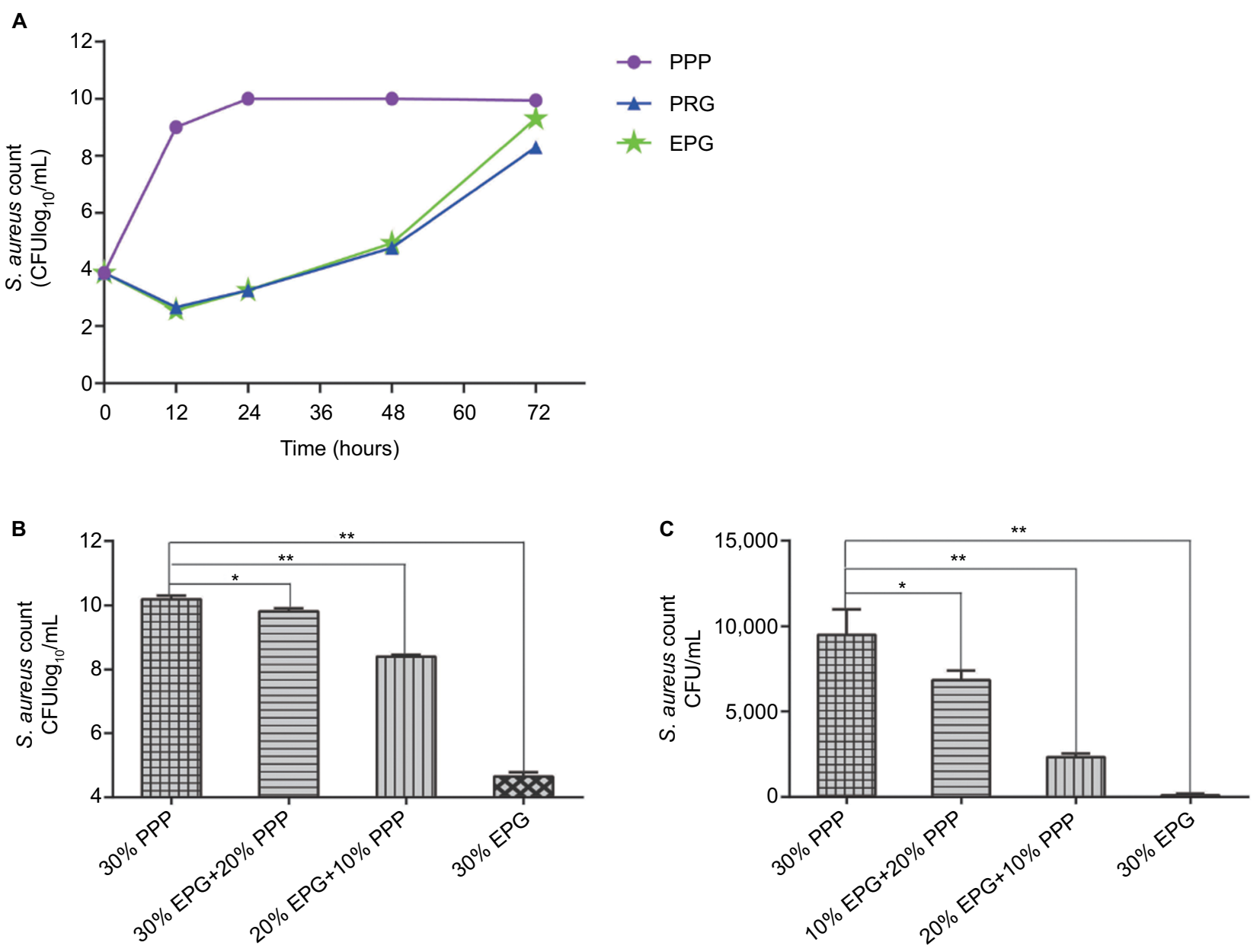

Figure 2 Comparison of antibacterial activity between PRG and EPG and antibacterial performance of EPG at different concentrations.

Notes: (A) Comparison of the effects of PRG and EPG on the growth of S. aureus. (B) Effects of different concentrations of EPG on the growth of extracellular S. aureus. (C) Effects of different concentrations of EPG on the growth of intracellular S. aureus. Viable bacteria were quantified by the colony plate counting method. Significant deviations from the $30 \%$ PPP group $(* P<0.05 ; * * P<0.01)$.

Abbreviations: EPG, extract liquid of platelet-rich gel; PPP, Platelet-poor plasma; PRG, platelet-rich gel; S. aureus, Staphylococcus aureus.

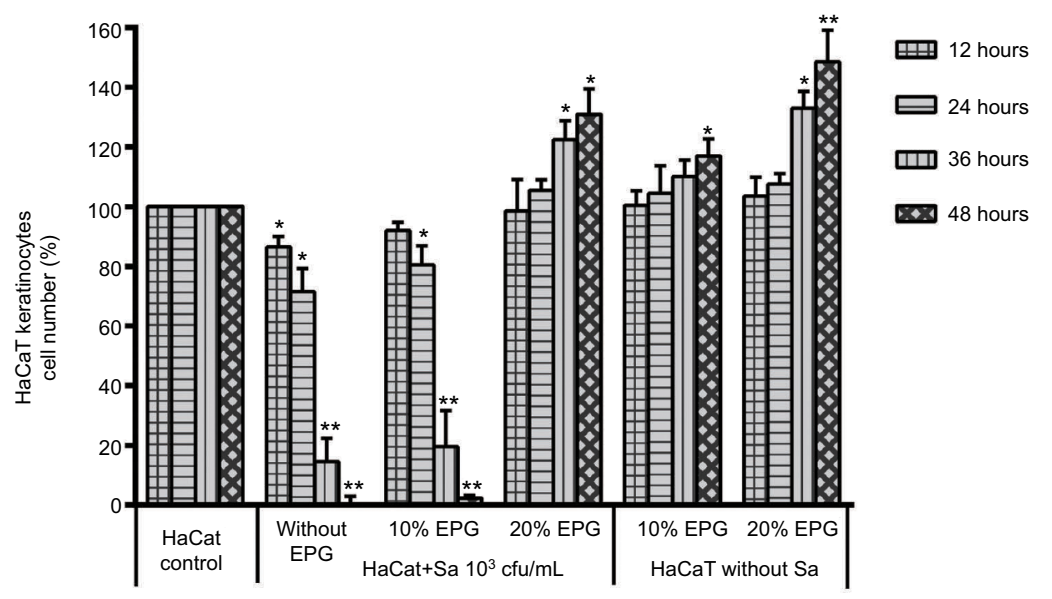

Figure 3 Amounts of $10 \%$ and $20 \%$ EPG were tested for their capacity to protect $\mathrm{HaCaT}$ cells from bacterial damage and promote $\mathrm{HaCaT}$ cells proliferation. Notes: Significant deviations from the $\mathrm{HaCaT}$ control at the respective incubation time $(* P<0.05 ; * * P<0.0 \mathrm{I})$.

Abbreviation: EPG, extract liquid of platelet-rich gel.

stimulated in the HS group at the 12th and 24th hour. After intervention with EPG, PDCD4 and p-NF-אB p65 proteins were significantly reduced when the HS was compared to the HSP group. Results associated with bacterial infection at the 48th hour were not reported because of insufficient protein extracted from residual $\mathrm{HaCaT}$ cells. In comparison 

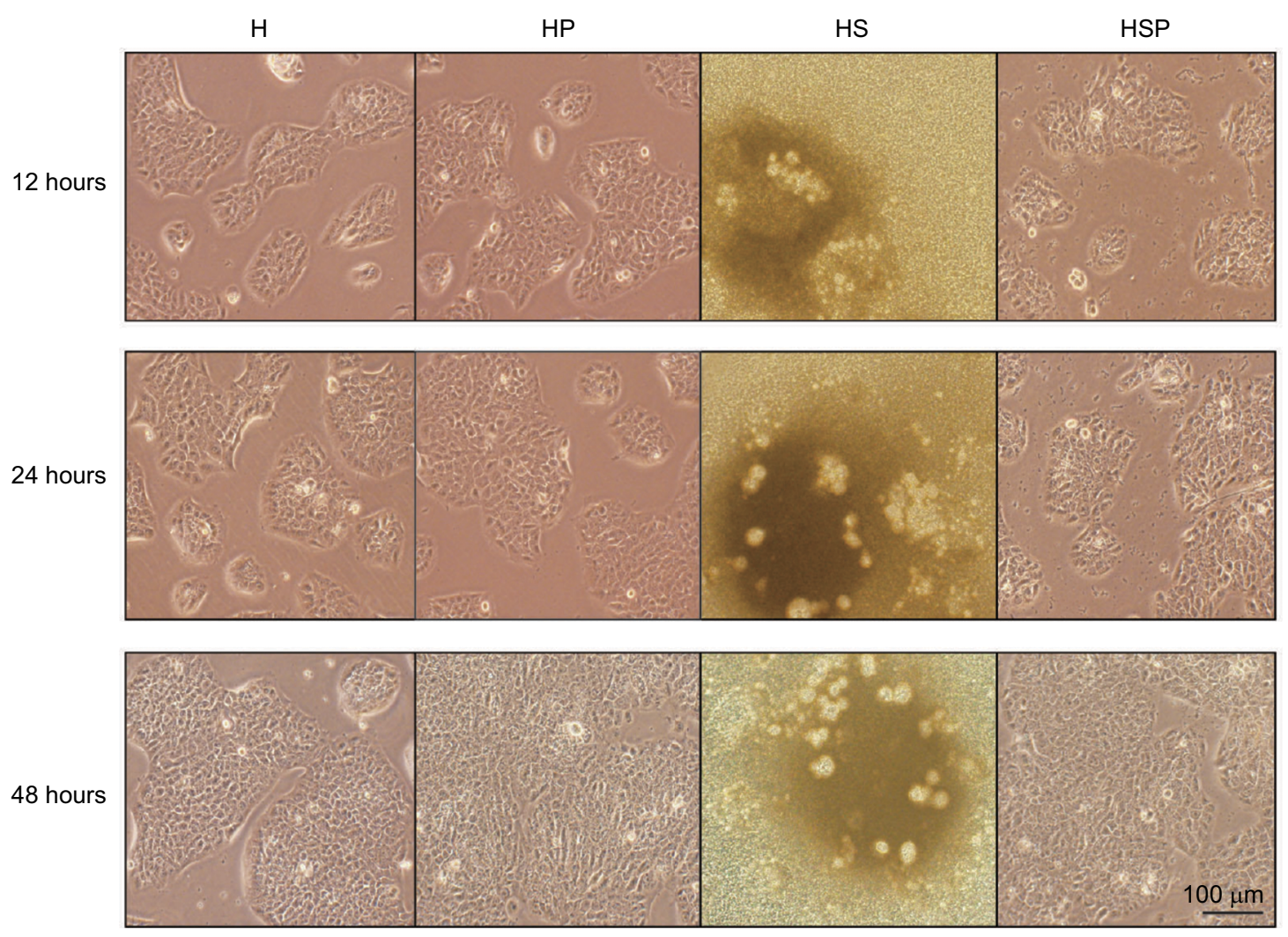

Figure 4 Images of the four groups under light microscope.

Notes: Photos were taken before extraction of RNA from HaCaT cells at various time points. Scale bar: $100 \mu \mathrm{m}$.

to the $\mathrm{H}$ group, $\mathrm{PDCD} 4$ and $\mathrm{p}-\mathrm{NF}-\mathrm{\kappa B}$ p 65 protein in the HP group were down-regulated by EPG at the 24th and 48th hour.

On the basis of detection in p-p65 protein expression, the translocations of p65 unit of NF- $\mathrm{KB}$ from cytosol to nucleus were determined in the four groups. As Figure 6 shows, antibody against NF-KB p65 produced red signal under fluorescence microscope, whereas the blue signal was produced by the DAPI staining of the cell nuclei. Areas where the red and the blue fluorescence overlapped appeared pink. In the $\mathrm{H}$ and $\mathrm{HP}$ groups, $\mathrm{HaCaT}$ cells exhibited red signal predominantly in the cytoplasm. Bacterial infection induced the pink staining in the HS group, indicating an increase in the nuclear translocation of NF- $\mathrm{KB}$ p 65 protein. While after intervention with EPG, significantly reduced intensity of pink fluorescence was observed in the HSP group, suggesting EPG blocked the nuclear translocation of the NF- $\mathrm{KB}$ p 65 protein.

\section{EPG promotes anti-inflammatory cytokines and inhibits pro-inflammatory cytokines}

To examine the effect of EPG intervention on inflammation during bacterial infection, the mRNA expressions and concentrations of anti-inflammatory (IL-10 and TGF- $\beta 1$ ) and pro-inflammatory cytokines (IL-6 and TNF- $\alpha$ ) were measured in $\mathrm{HaCaT}$ cells and cultured supernatant respectively (Figures 7 and 8). Bacterial infection promoted the expression and secretion of IL- 6 and TNF- $\alpha$ in the HS group. Whereas the intervention of EPG reduced the expression and release of these two pro-inflammatory cytokines in the HSP group, indicating an inhibition of inflammatory response. The same anti-inflammatory effect was also observed in the absence of bacterial infection in the HP group. In addition, a decrease in IL-10 expression and secretion were observed in the HS group but these were increased by EPG intervention in the HSP group. The expression and secretion of TGF- $\beta 1$ were also increased by EPG intervention in the HSP group.

\section{Discussion}

Metabolic disorders and immune abnormalities in patients with diabetes increase the susceptibility of wounds to bacterial infections. Infection further aggravates these ulcers and impedes the healing process. S. aureus is a resident bacterium of human skin and colonizes in wounds after skin damage. It is one of the dominant sources of bacterial infection in DFUs. ${ }^{3}$ Bacteria causes cell necrosis and apoptosis by invading cells and releasing toxins. Bacteria also activates the body's 

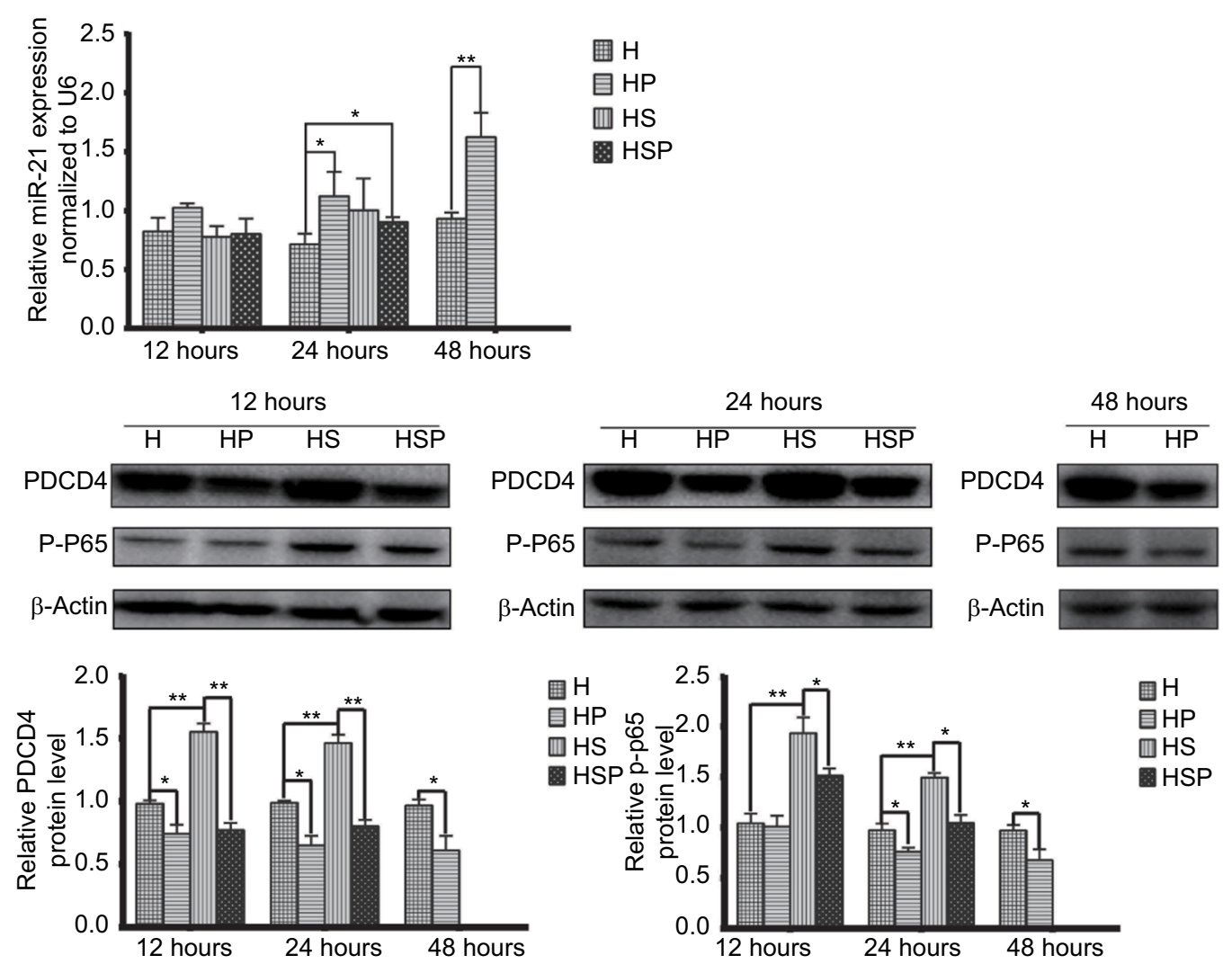

Figure 5 miR-2I, PDCD4 and phospho-NF- $\kappa$ B p65 (P-P65) level in HaCaT cells of the four groups.

Notes: PDCD4 and p-p65 increased because of bacterial infection but decreased by EPG at the 12th and 24th hour. Direct application of EPG to HaCaT cells down-regulated PDCD4 and p-p65 protein at the 24th and 48th hour. MiR-2I elevated with reduced PDCD4 and p-p65 at the 24th and 48th hour. In the setting of bacterial infection, results at the 48th hour are not shown because of insufficient RNA and protein extracted from the residual cells. Significant deviations from the HaCaT control at the respective incubation time $(* P<0.05 ; * * P<0.01)$.

Abbreviations: EPG, extract liquid of platelet-rich gel; PDCD4, programmed cell death factor 4.

immune system, stimulating release of tissue-lysing enzymes and ROS from immune cells to cause tissue damage; causing sustained or excessive inflammatory reactions, stagnation of the wound healing process in the inflammatory response period and failure to enter the proliferative phase. ${ }^{21}$ Keratinocytes are the most important cell types in the epidermis and normally participate in the formation of barriers and protect the body from invading foreign bodies and pathogens. In the process of wound healing, keratinocytes proliferate, migrate and differentiate, and finally complete the re-epithelialization process. ${ }^{22}$ In addition, keratinocytes play various roles in the immune response of the skin, such as antigen presentation, release of immune mediators, and secretion of various cytokines. $^{23}$ Thus, with reference to a previous study, ${ }^{24}$ we co-cultured human $\mathrm{HaCaT}$ keratinocytes with $S$. aureus under high-glucose conditions to establish an in-vitro high-glucose wound infection model. This model allows users to accurately set various conditions and avoid confounding factors. Compared to simple in-vitro antibacterial experiments, it is also possible to simultaneously observe the effects of bacteria and intervention on donor cells. The devised wound model is a good study tool for simulating the infected cells in DFUs and observing wound repair mechanism in vitro.

This study illustrates that HaCaT cells damaged by $S$. aureus appears to be concentration-dependent. The low concentration of bacteria causes cell proliferation to be severely impaired after 24 hours of co-culture, suggesting that $\mathrm{HaCaT}$ cells have immunomodulatory effects on their own, and have a certain resistance to low concentrations of $S$. aureus virulence in the early stages of cellular damage. High concentrations of bacteria exacerbate the rate of damage. PRG exhibits an antibacterial activity to $S$. aureus at various time-intervals within 72 hours, while PPP cannot exert this antibacterial effect, suggesting that activated platelets are the cornerstone of PRG function. These observations are consistent with previous reports. ${ }^{25,26}$ Platelets share many structural and functional properties with other native immune cells and thus play an important role in host immune defense. ${ }^{27}$ Platelets release alpha particles, antimicrobial peptides, chemokines, peroxides and other substances, all of which have antibacterial effect. These substances can directly inhibit or kill pathogens, and also exert indirect antibacterial 


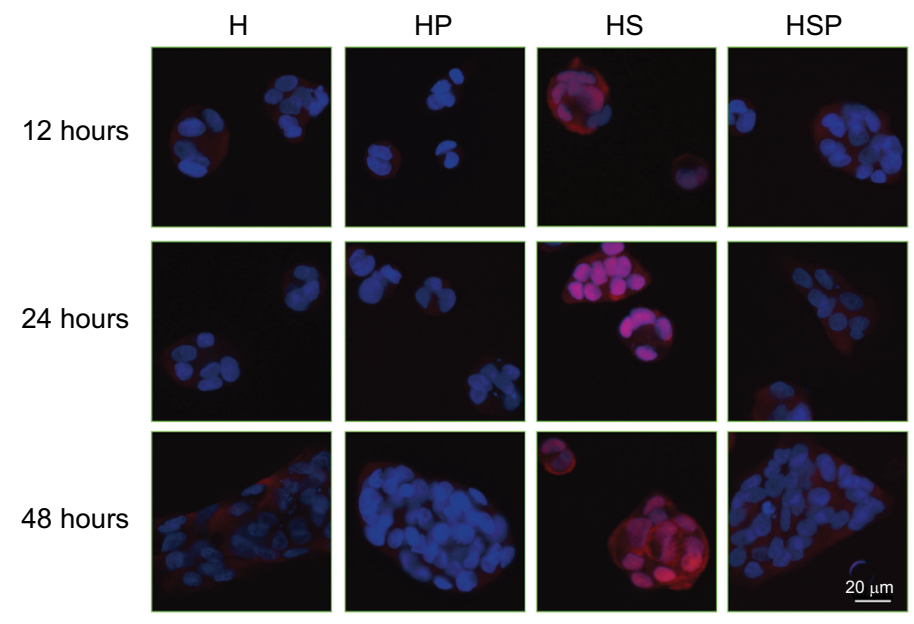

Figure 6 Immunofluorescence microscopy analysis of the spatial localization of the NF- $\kappa B$ p 65 protein.
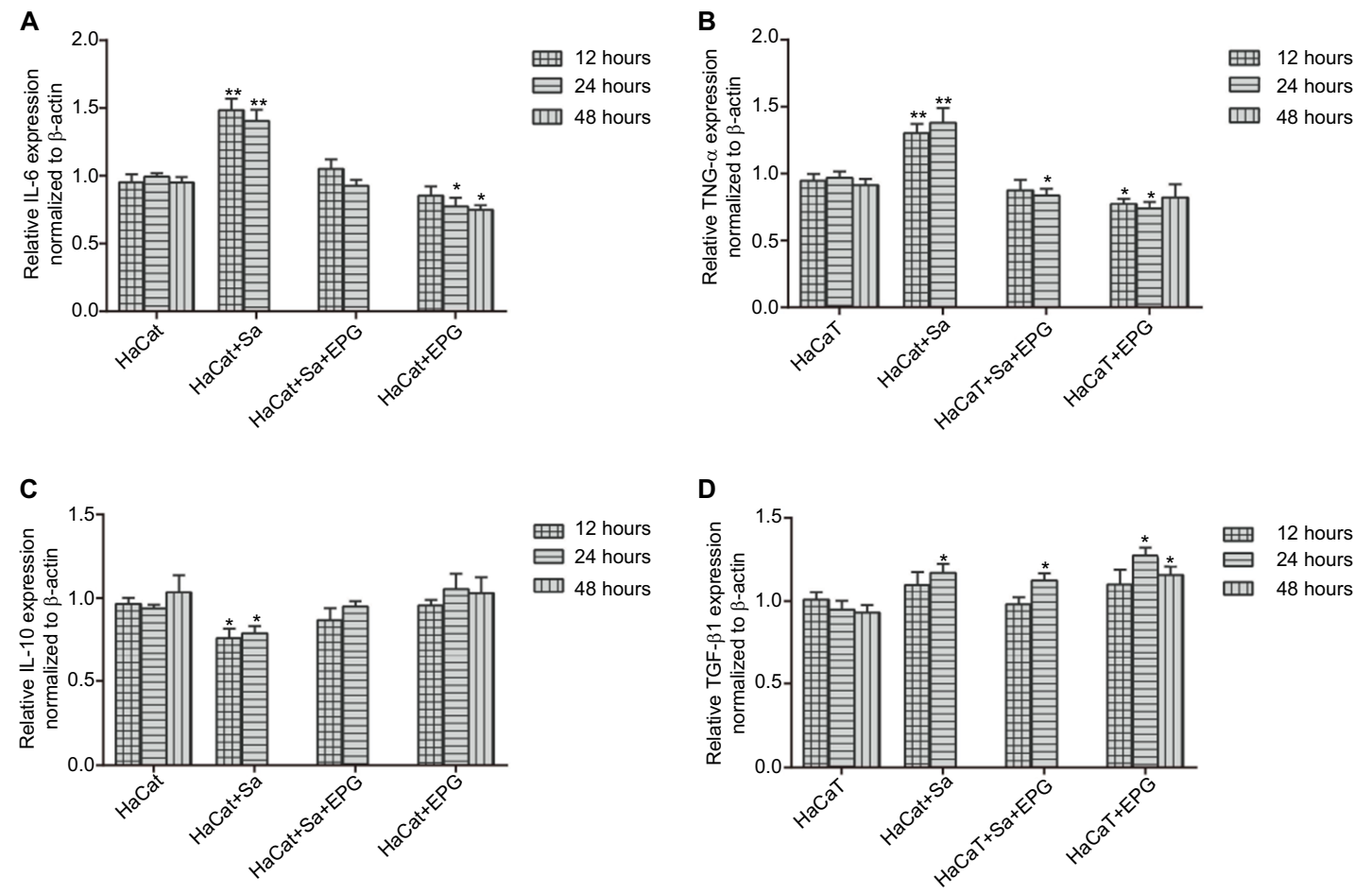

Figure 7 (A) IL-6, (B) IL-10, (C) TNF- $\alpha$, (D) TGF- $\beta$ I mRNA expression in HaCaT cells as measured by qRT-PCR.

Notes: In the setting of bacterial infection, results at the 48th hour are not shown because of insufficient RNA extracted from residual cells. Significant deviations from the $\mathrm{HaCaT}$ control at the respective incubation time $(* P<0.05 ; * * P<0.0 \mathrm{I})$.

Abbreviations: EPG, extract liquid of platelet-rich gel; qRT-PCR, quantitative reverse transcription; TNF- $\alpha$, tumor-necrosis factor alpha.

effects through chemotaxis and activation of immune cells. ${ }^{28}$ Platelet concentration in PRG is three to five times that of normal human blood, and large amounts of active substances are released after platelet activation, which forms the basis of PRG to exhibit modest antibacterial effect.

In view of the fact that the jelly-like nature of PRG was difficult to pipette accurately, we extracted EPG from
PRG. Our study showed that both of them had equivalent antibacterial capacity within 48 hours, but PRG had a more lasting antibacterial effect than EPG. This phenomenon, on the one hand, may suggest that our extraction method could not completely obtain the platelets and their released substances in PRG. On the other hand, it may also be related to the three-dimensional scaffold structure formed by fibrin 
A

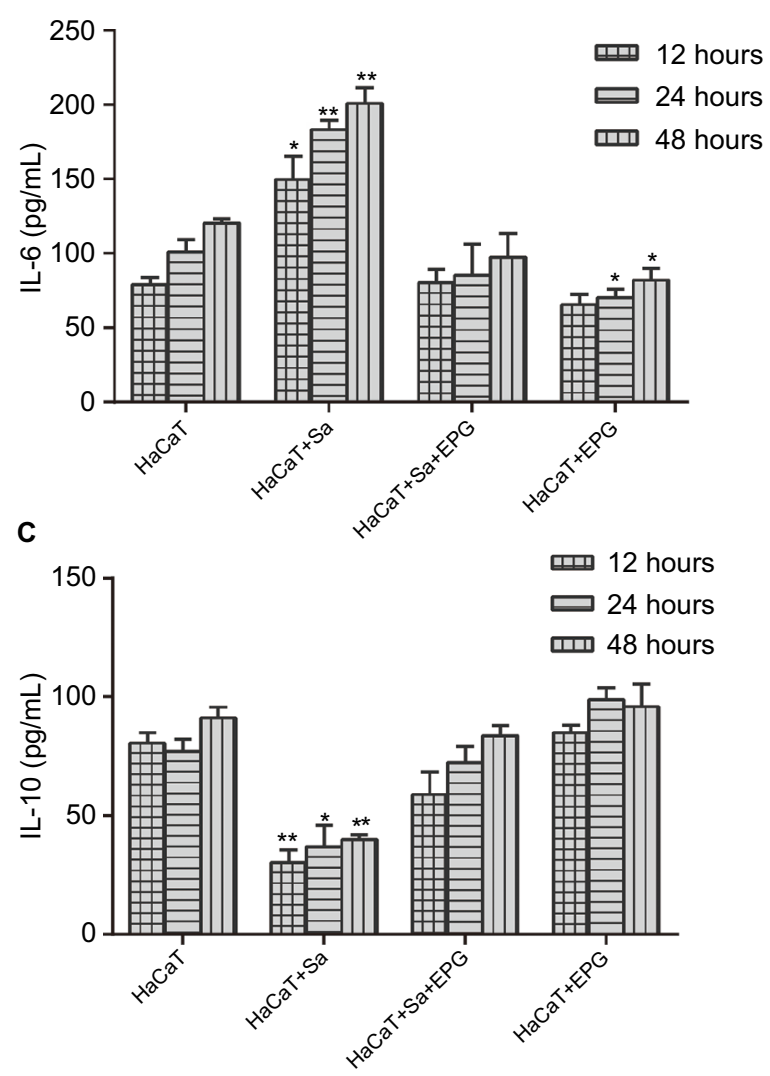

B
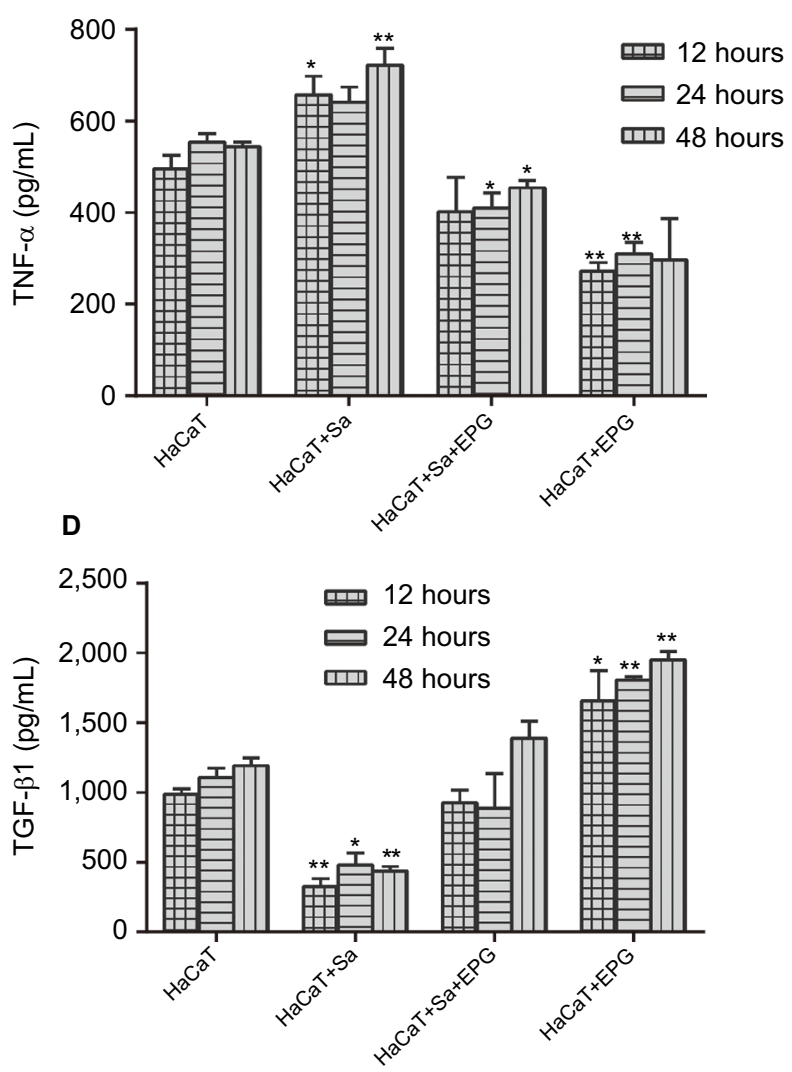

Figure 8 (A) IL-6, (B) IL-I0, (C) TNF- $\alpha$, (D) TGF- $\beta$ I content in the supernatant as determined by ELISA. Notes: Significant deviations from the $\mathrm{HaCaT}$ control at the respective incubation time $(* P<0.05 ; * * P<0.01)$. Abbreviations: EPG, extract liquid of platelet-rich gel; TNF- $\alpha$, tumor-necrosis factor alpha.

polymerization in PRG, adhering to active substances released by platelets and slowly releasing these active substances. ${ }^{29}$ The sustained-release effect that leads to a more long-lasting therapeutic effect also necessitates the need for the replacement of PRG after covering the wound for 5 days in clinical treatment. However, EPG is considered a more suitable candidate for micro-manipulation, owing to its convenience and accuracy in a liquid form. Combined with the comparative results of antibacterial activity, we believe that EPG was an effective substitute for PRG in experiments within 48 hours, and this finding has not yet been reported before. EPG is found to play a role in our concentration-dependent model. An amount of $20 \%$ of EPG can significantly inhibit intracellular and extracellular $S$. aureus, protect $\mathrm{HaCaT}$ cells against $S$. aureus infection, and promote cell proliferation. In the absence of $S$. aureus infection, EPG promotes cell proliferation more strongly.

miRNAs are a class of small, non-coding, singlestranded RNAs that specifically recognize and bind to a target messenger RNA (mRNA), causing degradation of the mRNA or hindering its translation, thereby allowing posttranscriptional regulation of the gene. ${ }^{30}$ Among the miRNA family, miRNA-21 is considered an important member which is involved in the proliferation, differentiation, and apoptosis of regulated cells and associated with the occurrence and prognosis of a variety of tumors. ${ }^{31}$ Studies have also suggested that miRNA-21 may stimulate re-epithelization of the wound surface. ${ }^{16,32}$ PDCD4 is a tumor suppressor regulated by miRNA-21 and inhibits cell proliferation by blocking protein translation in eukaryotic cells. The absence or low expression of PDCD4 is associated with tumorigenesis. ${ }^{33}$ It has been reported that up-regulation of miRNA-21 in lipopolysaccharide-stimulated peripheral blood mononuclear cells can reduce PDCD4, inhibit NF- $\mathrm{KB}$ activity and increase IL-10 expression. ${ }^{34}$ It has also been reported that increased PDCD4 expression in coronary microembolized porcine cardiomyocytes will increase NF- $\mathrm{\kappa B}$ activity which result in an increase of TNF- $\alpha .{ }^{35}$ In either way, PDCD4 can activate $\mathrm{NF}-\kappa \mathrm{B}$ signaling pathway to influence the regulation 
of inflammation. NF- $\kappa \mathrm{B}$ is an important transcriptional regulator that specifically binds to promoters and enhancers of various genes and plays an important role in the body's immune response through its regulation of the expression of cytokines, adhesion molecules, chemokines, and immune receptors. ${ }^{36}$ The most common form of NF- $\kappa \mathrm{B}$ is a dimeric form consisting of two family members of the p50 and p65 and is inactivated via the binding with IKB. Upon activation, I $\kappa \mathrm{B}$ is degraded, p65 is phosphorylated, and NF- $\kappa \mathrm{B}$ is transported from the nucleus into the cytoplasm and functions as a transcription regulator. ${ }^{37}$

This study found that $S$. aureus infection caused a simultaneous increase in the levels of PDCD4 and phosphorylated p65 (p-p65) in HaCaT cells. The increase in PDCD4 partially explained the impaired cell proliferation induced by bacterial infection, while the increase in p-p65 and its translocation from cytosol to nucleus reflected the activation of the NF- $\kappa B$ signaling pathway. After 12 hours of EPG intervention, we found that both PDCD4 and p-p65 were down-regulated and the translocation of p65 was significantly reduced, but upregulation of miRNA-21 was not yet statistically significant at this time point. We speculated that EPG-mediated upregulation of miRNA-21 was a relatively slow process. The down-regulation of PDCD4 and p-p65 in the early stage was mainly attributed to the bacteriostatic effect of EPG. After 24 hours of EPG intervention, we found that up-regulation of miRNA-21 in HaCaT cells were coordinated by the downregulation of PDCD4 and p-p65, as well as the reduced p65 translocation to the nucleus. We speculated that this phenomenon was partially related to the inhibition on bacteria by EPG. In addition, it may also be attributed to the up-regulation of miRNA-21 by EPG and subsequent down-regulation of PDCD4 and inhibition of NF- $\mathrm{KB}$ activity. In the absence of bacterial infection, we used EPG to directly intervene in the cellular activity, in which the up-regulation of miRNA-21 appeared at the 24th hour but the degree of up-regulation was more pronounced at the 48th hour. This phenomenon also further supported our hypothesis. Synchronous reduction of PDCD4 and p-p65 observed with increased miRNA-21 in sterile conditions confirmed that EPG could regulate PDCD4 through miRNA-21 and thus affected the NF- $\kappa B$ signaling pathway, regardless of its antibacterial effect.

The pro-inflammatory cytokines, IL- 6 and TNF- $\alpha$ accumulate in large amounts at the DFUs' wound surface, making it difficult for inflammation to subside and aggravating tissue damage. ${ }^{5,38}$ Anti-inflammatory cytokine IL-10 can promote tissue repair by inhibiting these inflammatory responses. ${ }^{5}$
TGF- $\beta 1$ can promote the proliferation, migration and differentiation of fibroblasts, accelerate epithelial-mesenchymal transition, coordinate the action of other growth factors, and facilitate wound healing. ${ }^{39}$ In the present study, it was found that the up-regulation of IL- 6 and TNF- $\alpha$ caused by $S$. aureus infection was consistent with the activation of the NF- $\kappa B$ signaling pathway, and the down-regulation of IL-10 and TGF- $\beta 1$ also reflects the perverse healing effect caused by the antibacterial infection. After intervention with EPG, the changes of the above-mentioned cytokines can be reversed; the anti-inflammatory cytokines are increased whereas the pro-inflammatory factors are reduced. In the absence of bacterial infection, direct action of EPG on cells validates this anti-inflammatory effect. Combined with the detection of relevant signal molecules, we consider miRNA-21/PDCD4/ $\mathrm{NF}-\kappa \mathrm{B}$ signaling pathway as a direct mechanism for EPG to exert its anti-inflammatory effects, and that EPG also indirectly produces an anti-inflammatory effect by inhibiting bacterial growth and reducing harmful stimuli.

miRNA-21 may play an important role in PRG mediating anti-inflammation and promoting wound repair, and provide further theoretical support for PRG to effectively treat DFUs in clinical practice. Yet our studies have presented some deficiencies. At present, we have not been able to elucidate the mechanism of miRNA-21 changes in HaCaT cells. It has been reported that platelet-released exosomes are rich in miRNAs, and these exosomes can be taken up by other cells, ${ }^{40}$ suggesting that this change may be due to the direct release of miRNA-21 from platelets. It has also been reported that platelet-released growth factors, such as TGF- $\beta$ can up-regulate miRNA-21, ${ }^{41}$ suggesting that this change may also be the result of the action of other platelet-derived substances. Further study is required to elaborate these changes. In addition, the elevated mRNA expression of TGF- $\beta$ is contradicted by its reduced content in supernatants. This phenomenon may be involved in mRNA translation, protein modification, and protein secretion. The uncertain regulatory mechanism in these processes deserves our further study.

\section{Conclusion}

In conclusion, the high-glucose in vitro infection wound model established may be a valuable tool for future similar research. miRNA-21 appears to regulate NF- $\mathrm{kB}$ through PDCD4 and play a triple role of antibacterial, anti-inflammatory while stimulating cell proliferation in the diabetic wound model. Therefore, we speculate that miRNA-21 is a 
promising intervention target and may provide new strategies for the treatment of refractory wounds such as DFUs.

\section{Acknowledgment}

This work was supported by the National Nature Science Foundation of China (Grant No. 81500596).

The abstract of this paper was presented at the " 54 th EASD Annual Meeting of the European Association for the Study of Diabetes" as an oral presentation.

\section{Disclosure}

The authors report no conflicts of interest in this work.

\section{References}

1. Ogurtsova K, da Rocha Fernandes J D, Huang Y, et al. IDF Diabetes Atlas: Global estimates for the prevalence of diabetes for 2015 and 2040. Diabetes Res Clin Pract. 2017;128:40-50.

2. Armstrong DG, Boulton AJM, Bus SA. Diabetic foot ulcers and their recurrence. $N$ Engl J Med. 2017;376(24):2367-2375.

3. Lavery LA, Davis KE, Berriman SJ, et al. WHS guidelines update: diabetic foot ulcer treatment guidelines. Wound Repair Regen. 2016;24(1):112-126.

4. Spichler A, Hurwitz BL, Armstrong DG, Lipsky BA. Microbiology of diabetic foot infections: from Louis Pasteur to "crime scene investigation'. BMC Med. 2015;13:2.

5. Acosta JB, del Barco DG, Vera DC, et al. The pro-inflammatory environment in recalcitrant diabetic foot wounds. Int Wound $J$. 2008;5(4):530-539.

6. Salazar JJ, Ennis WJ, Koh TJ. Diabetes medications: impact on inflammation and wound healing. J Diabetes Complications. 2016;30(4):746-752.

7. Lipsky BA. Diabetic foot infections: current treatment and delaying the 'post-antibiotic era'. Diabetes Metab Res Rev. 2016;32(Suppl 1):246-253

8. Deng W, Boey J, Chen B, et al. Platelet-rich plasma, bilayered acellular matrix grafting and negative pressure wound therapy in diabetic foot infection. $J$ Wound Care. 2016;25(7):393-397.

9. Saad Setta H, Elshahat A, Elsherbiny K, Massoud K, Safe I. Platelet-rich plasma versus platelet-poor plasma in the management of chronic diabetic foot ulcers: a comparative study. Int Wound J. 2011;8(3):307-312.

10. Picard F, Hersant B, Bosc R, Meningaud JP. The growing evidence for the use of platelet-rich plasma on diabetic chronic wounds: a review and a proposal for a new standard care. Wound Repair Regen. 2015;23(5):638-643.

11. Burnouf T, Chou ML, Wu YW, Su CY, Lee LW. Antimicrobial activity of platelet (PLT)-poor plasma, PLT-rich plasma, PLT gel, and solvent/ detergent-treated PLT lysate biomaterials against wound bacteria. Transfusion. 2013;53(1):138-146.

12. Mercier RC, Dietz RM, Mazzola JL, Bayer AS, Yeaman MR. Beneficial influence of platelets on antibiotic efficacy in an in vitro model of Staphylococcus aureus-induced endocarditis. Antimicrob Agents Chemother. 2004;48(7):2551-2557.

13. Etulain J. Platelets in wound healing and regenerative medicine. Platelets. 2018;29(6):556-568.

14. Nagalla S, Shaw C, Kong X, et al. Platelet microRNA-mRNA coexpression profiles correlate with platelet reactivity. Blood. 2011;117(19):5189-5197.

15. Banerjee J, Chan YC, Sen CK. MicroRNAs in skin and wound healing. Physiol Genomics. 2011;43(10):543-556.

16. Madhyastha R, Madhyastha H, Nakajima Y, Omura S, Maruyama M. MicroRNA signature in diabetic wound healing: promotive role of miR-21 in fibroblast migration. Int Wound J. 2012;9(4):355-361.

17. Roy S, Sen CK. miRNA in innate immune responses: novel players in wound inflammation. Physiol Genomics. 2011;43(10):557-565.
18. Asangani IA, Rasheed SA, Nikolova DA, et al. MicroRNA-21 (miR21) post-transcriptionally downregulates tumor suppressor Pdcd4 and stimulates invasion, intravasation and metastasis in colorectal cancer. Oncogene. 2008;27(15):2128-2136.

19. Frankel LB, Christoffersen NR, Jacobsen A, Lindow M, Krogh A, Lund AH. Programmed cell death 4 (PDCD4) is an important functional target of the microRNA miR-21 in breast cancer cells. J Biol Chem. 2008;283(2):1026-1033.

20. Ma X, Becker Buscaglia LE, Barker JR, Li Y. MicroRNAs in NF-kappaB signaling. J Mol Cell Biol. 2011;3(3):159-166.

21. Bertesteanu S, Triaridis S, Stankovic M, et al. Polymicrobial wound infections: pathophysiology and current therapeutic approaches. Int J Pharm. 2014;463(2):119-126.

22. Hosoya A, Lee JM, Cho SW, et al. Morphological evidence of basal keratinocyte migration during the re-epithelialization process. Histochem Cell Biol. 2008;130(6):1165-1175.

23. Nestle FO, Di Meglio P, Qin JZ, Nickoloff BJ. Skin immune sentinels in health and disease. Nat Rev Immunol. 2009;9(10):679-691.

24. Wiegand C, Abel M, Ruth P, Hipler UC. HaCaT keratinocytes in coculture with Staphylococcus aureus can be protected from bacterial damage by polihexanide. Wound Repair Regen. 2009;17(5):730-738.

25. Yeaman MR. Platelets: at the nexus of antimicrobial defence. Nat Rev Microbiol. 2014;12(6):426-437.

26. Martineau I, Lacoste E, Gagnon G. Effects of calcium and thrombin on growth factor release from platelet concentrates: kinetics and regulation of endothelial cell proliferation. Biomaterials. 2004;25(18):4489-4502.

27. Hamzeh-Cognasse H, Damien P, Chabert A, Pozzetto B, Cognasse F, Garraud O. Platelets and infections - complex interactions with bacteria. Front Immunol. 2015;6:82.

28. Deppermann C, Kubes P. Platelets and infection. Semin Immunol. 2016;28(6):536-545.

29. Dohan DM, Choukroun J, Diss A, et al. Platelet-rich fibrin (Prf): a second-generation platelet concentrate. Part II: platelet-related biologic features. Oral Surg Oral Med Oral Pathol Oral Radiol Endod. 2006;101(3):e45-e50.

30. Ambros V. MicroRNA pathways in flies and worms: growth, death, fat, stress, and timing. Cell. 2003;113(6):673-676.

31. Wang W, Li J, Zhu W, et al. MicroRNA-21 and the clinical outcomes of various carcinomas: a systematic review and meta-analysis. $B M C$ Cancer. 2014;14:819.

32. Wang T, Feng Y, Sun H, et al. miR-21 regulates skin wound healing by targeting multiple aspects of the healing process. Am J Pathol. 2012;181(6):1911-1920.

33. Yang HS, Jansen AP, Komar AA, et al. The transformation suppressor Pdcd4 is a novel eukaryotic translation initiation factor 4A binding protein that inhibits translation. Mol Cell Biol. 2003;23(1):26-37.

34. Sheedy FJ, Palsson-McDermott E, Hennessy EJ, et al. Negative regulation of TLR4 via targeting of the proinflammatory tumor suppressor PDCD4 by the microRNA miR-21. Nat Immunol. 2010;11(2):141-147.

35. Su Q, Li L, Zhao J, Sun Y, Yang H. Effects of trimetazidine on PDCD4/ NF- $\kappa \mathrm{B} / \mathrm{TNF}-\alpha$ pathway in coronary microembolization. Cell Physiol Biochem. 2017;42(2):753-760.

36. Karin M, Greten FR. NF-kappaB: linking inflammation and immunity to cancer development and progression. Nat Rev Immunol. 2005;5(10):749-759.

37. Li Q, Verma IM. NF-kappaB regulation in the immune system. Nat Rev Immunol. 2002;2(10):725-734.

38. Dinh T, Tecilazich F, Kafanas A, et al. Mechanisms involved in the development and healing of diabetic foot ulceration. Diabetes. 2012;61(11):2937-2947.

39. Gorelik L, Flavell RA. Transforming growth factor-beta in T-cell biology. Nat Rev Immunol. 2002;2(1):46-53.

40. Stakos DA, Gatsiou A, Stamatelopoulos K, Tselepis AD, Stellos K. Platelet microRNAs: from platelet biology to possible disease biomarkers and therapeutic targets. Platelets. 2013;24(8):579-589.

41. Wang T, Zhang L, Shi C, et al. TGF- $\beta$-induced miR- 21 negatively regulates the antiproliferative activity but has no effect on EMT of TGF- $\beta$ in HaCaT cells. Int J Biochem Cell Biol. 2012;44(2):366-376. 
Infection and Drug Resistance is an international, peer-reviewed openaccess journal that focuses on the optimal treatment of infection (bacterial, fungal and viral) and the development and institution of preventive strategies to minimize the development and spread of resistance. The journal is specifically concerned with the epidemiology of antibiotic resistance and the mechanisms of resistance development and diffusion in both hospitals and the community. The manuscript management system is completely online and includes a very quick and fair peerreview system, which is all easy to use. Visit http://www.dovepress.com/ testimonials.php to read real quotes from published authors.

Submit your manuscript here: https://www.dovepress.com/infection-and-drug-resistance-journal 